\title{
CORRIGENDUM
}

\section{Testing the accuracy of an observation-based classifier for rapid detection of autism risk}

M Duda, JA Kosmicki and DP Wall

Translational Psychiatry (2014) 4, e440; doi:10.1038/tp.2014.86; published online 9 September 2014

Correction to: Translational Psychiatry (2014) 4, e424; doi:10.1038/ tp.2014.65; published online 12 August 2014

Following publication, the authors noted that a reference was omitted from the reference list. The citation should appear in the third sentence of the last paragraph of the paper, where ref. 20 was cited erroneously. The omitted reference appears as:
Fusaro VA, Daniels J, Duda M, Deluca TF, D’Angelo O, Taburello J et al. The potential of accelerating early detection of autism through content analysis of YouTube videos. PLoS One 2014; 9: e93533. 